
\title{
25 Research Square \\ The value of a patient global assessment in management of sarcoidosis
}

Robert Baughman ( $\nabla$ baughmrp@ucmail.uc.edu )

University of Cincinnati Medical Center https://orcid.org/0000-0003-4871-3862

Jeffrey Kotzin

University of Cincinnati College of Medicine

Elyse E Lower

University of Cincinnati College of Medicine

\section{Research Article}

Keywords: quality of life, sarcoidosis treatment, prednisone, visual analogue scale

Posted Date: March 23rd, 2021

DOI: https://doi.org/10.21203/rs.3.rs-338031/v1

License: (1) This work is licensed under a Creative Commons Attribution 4.0 International License.

Read Full License

Version of Record: A version of this preprint was published at Lung on July 13th, 2021. See the published version at https://doi.org/10.1007/s00408-021-00455-5. 


\section{Abstract}

The patient global assessment (PGA) is a reported outcome instrument used to gauge the patient's wellbeing. We performed a prospective study of patients seen at the University of Cincinnati Sarcoidosis Clinic. Two groups were studied: those at first visit during the time period (Initial) and those seen at least one more time by the same physician (Follow-up). A total of 1006, including 677 Initial visits, occurred during the six month period. Patients who initiated or increased their anti-inflammatory therapy had a significantly lower mean PGA score (ANOVA $P<0.001, p<0.05$ for increased versus all others). There was no significant difference in initial PGA score based on race, sex, or age. The change in PGA was significantly lower for those who increased medication (ANOVA $P<0.001$, increased different from all others, $p<0.05$ ). The PGA was significantly lower for patients who increased anti-inflammatory therapy initially or at follow-up, however there was overlap between groups.

\section{Introduction}

Because patients with multi-organ sarcoidosis often experience a wide array of symptoms, disease assessment and treatment response may involve more than one dimension ${ }^{1}$. For example, forced vital capacity is an objective measure of lung function ${ }^{2}$ but fails to provide information regarding other disease aspects and the effect on overall health. Patient reported outcomes (PROs) in sarcoidosis have been developed to provide more comprehensive assessment of the impact of sarcoidosis on the patient's health ${ }^{3 ; 4}$. Changes in these instruments have been documented with various treatment regimens for sarcoidosis ${ }^{5-7}$.

Although PROs may be important research tools to assess sarcoidosis outcome, these questionnaires may require five to thirty minutes to complete ${ }^{8}$. In contrast, the patient global assessment (PGA) is a ten point scale with a MCID of two points ${ }^{9}$ which can be completed in less than a minute. It is similar to the pain scale, which has been widely adapted to clinical practice ${ }^{10}$. The treatment of sarcoidosis is designed to relieve symptoms and avoid danger ${ }^{11}$. The use of a scale to summarize disease impact by the patient at a clinic visit may facilitate treatment decisions in daily practice.

The purpose of this study was to determine the feasibility of adapting a PGA as an assessment tool in a sarcoidosis clinic. The results of the PGA were compared to the treatment decisions made at individual clinic visits. The influence of race, gender, age, organs affected, and baseline treatment for sarcoidosis were compared to the PGA results.

\section{Methods}

This was a prospective study of all patients seen by either RPB or EEL at the University of Cincinnati Sarcoidosis Clinic from January 1, 2020 to June 30, 2020. Using a Likert scale from 1-10 with one the worst and 10 the best, the patient rated how he/she felt regarding sarcoidosis on the day of visit. Data collected included race, sex, age, current anti-inflammatory therapy, and organ involvement. Anti- 
inflammatory therapies and doses captured included glucocorticoids (e.g. prednisone), methotrexate, azathioprine, leflunomide, hydroxychloroquine, infliximab (or biosimilar), adalimumab, rituximab, and repository corticotropin injection $(\mathrm{RCl})$. Organ involvement was assessed using WASOG criteria for highly probable or probable disease ${ }^{12}$. The information was recorded in an electronic data capturing database (REDCap) ${ }^{13}$. The study was approved by the University of Cincinnati Institutional Review Board and registered on ClinicalTrials.gov (ClinicalTrials.gov Identifier: NCT02356445).

The decision to change anti-inflammatory therapy was performed by the physician during the clinic visit, and it was captured as increased, decreased or unchanged. An increase in medications was defined as:

1) current anti-inflammatory medication dosage increase; 2) a new anti-inflammatory therapy added with no change in other medications; 3 ) a new medication was added and another drug (for example prednisone) was reduced or withdrawn; 4) short course of increased glucocorticoids was prescribed. For cases where treatment was modified, the treating physician recorded the reason as disease worsening, acute infection, toxicity, or other.

Two sarcoidosis groups were studied: patients at first visit (Initial) and patients seen at least one more time during the study period by the same physician (Follow-up). For Follow-up patients, the change in PGA was calculated by subtracting the prior visit score from the current visit.

Statistics: Statistical analysis was performed using MedCalc software (Ostend, Belgium). Comparisons were made between groups using analysis of variance (ANOVA). If the ANOVA analysis found a significant difference between groups, a pairwise comparison was made between groups using the Scheffe test. A p value of $<0.05$ was considered significant for the ANOVA and pairwise comparison. To determine the cut-off for PGA scores for increase medication versus no change or reduction of medication, we performed a receiver operator curve (ROC) and calculated the area under the curve (AUC). A p value of $<0.05$ was considered significant.

\section{Results}

A total of 1006 sarcoidosis patient visits occurred during the six months of study. In all but $13(1.3 \%)$, complete information was recorded. After exclusion for unclear/missing visit information, full analysis was completed on 677 of 687 sarcoidosis patients with at least one initial visit with complete data. Table 1 depicts the clinical features of these 677 patients. Over a third of patients increased medications at the visit, and forty percent had no medication changes. A small difference in age was noted between groups (ANOVA $p<0.05$ ) with no differences for sex or self-declared race.

Table 2 compares anti-inflammatory change to PGA scores (ANOVA $p<0.001, p<0.05$ for increased versus all others). There were no significant differences among treatment groups based on age, sex, or self declared race. The PGA scores for increased treatment were significantly lower compared to the other scenarios. For all but rituximab, there was a significant difference for the PGA scores between the three treatment regimens with no difference between reduced medication and no change in medication. For 
rituximab there was no difference between treatment groups but there were only three patient visits where the treatment was increased.

Table 3 lists the PGA scores for those patients changed medications at the initial visit versus the reported indication for change in treatment. For patients who increased the anti-inflammatory medication or a new medication was added, the PGA score for toxicity was higher $(7.44 \pm 1.944)$ compared to patients who increased medication due to disease activity $(5.06 \pm 1.991)$ or acute infection by paired analysis $(P<0.05)$. Using paired analysis, patients who decreased anti-inflammatory medication due to disease activity had lower PGA scores compared to those who reduced for toxicity $(P<0.05)$. At only one visit was antiinflammatory medication reduced in the setting of infection. In that case, an antibiotic was prescribed and the dose of prednisone was unchanged but rituximab was held. Patients not on anti-inflammatory medications were ineligible for analysis of medication reduction.

A total of 316 paired visits were evaluable. Table 3 reveals PGA score changes from prior visit to current visit compared to concurrent treatment decisions. The PGA score was significantly lower if antiinflammatory medications were increased (number visits $=71$, Change PGA $-0.58 \pm 2.511$ ) compared to reduced medications (number visits $=82$, Change $P G A=0.74 \pm 2.054$ ) no change in medication (number of visits $=159$, Change $P G A=0.39 \pm 1.942$ ) or not receiving medications (number of visits $=4$, Change $P G A=3.25 \pm 1.893$ ) (ANOVA $<0.0001, p<0.05$ for increased versus each other treatment by paired analysis). No significant differences were noted in Change PGA scores based on gender, race, or age (data not shown).

Receiver operator curve (ROC) analysis determined that a PGA score of 6 or less was associated with an increase in medication with a $73 \%$ sensitivity and $71 \%$ specificity and AUC of $0.789(p<0.0001)$. There were 308 paired visits in which patients were receiving anti-inflammatory therapy at the second visit. A decrease in the PGA of 1 or more points was associated with an increase in medications with a sensitivity of $46 \%$, specificity of $74 \%$ (AUC $=0.624, p<0.005)$. Medications were increased in more than half of the patients with no change in PGA scores.

\section{Discussion}

Using the data collected in over $98 \%$ of 1006 clinic visits, the PGA was a fast and easy assessment tool for sarcoidosis patients. Significantly lower PGA scores indicated worse clinical status for those patients who required anti-inflammatory treatment increases. In a prospective study, the MCID for PGA was 2 points ${ }^{9}$. In the current study, patients who increased medication had a PGA scores 1.94 lower than those who reduced medications and 2.2 lower than those without medication change. Furthermore, the PGA scores were significantly lower for patients who increased medication regardless of race, sex, age, organ involvement, or therapy.

Significant changes in PGA scores were identified most frequently in patients who increased medications compared to other treatment options. When we analyzed race, sex, or age, the PGA score was still 
significantly lower for those who had medications increased versus other treatment subgroups. The average PGA score for patients increasing medication was not significantly different between the various subgroups. Similarly, no change was found in PGA scores for different treatment regimens versus organ involvement (Table 2). These findings support that PGA scores can be efficacious for most sarcoidosis phenotypes regardless of clinical or demographic features.

Although the PGA score performed well for the entire population studied, it was of more limited value for daily decision. Overall, PGA scores of $\leq 6$ were associated with increased medication at that visit with a sensitivity of $73 \%$ and specificity of $71 \%$. However, no medication change was made in over $20 \%$ of patients with a PGA score of 1 or 2 .

To enhance the potential value of PGA, we calculated the change in PGA from the previous visit. Patients who increased medication reported average scores of -0.58 while the average change of 0.74 was made for patients who reduced medications. Using ROC analysis, a one point change in PGA was associated with a treatment change but with only a sensitivity of $46 \%$ and specificity of $74 \%$.

The limitation of a PRO in daily practice has been noted by others. For example, a study of successful therapy for fibromyalgia found large variability for individual patients, but significant changes for the whole group ${ }^{14}$. The self-reported pain scale has been touted as providing a rapid assessment of pain ${ }^{15}$. This scale reduced the time for initiating analgesia in the emergency room ${ }^{16 ; 17}$. However, applying the pain scale with an algorithm was associated with higher total amounts of analgesia ${ }^{16 ; 18}$.

In conclusion, this study reveals the ease and clinical applicability of Patient Global Assessment for various sarcoidosis phenotypes and demographics. The lower the PGA score, the greater the likelihood that the patient would increase medication. This further supports the use of PGA in clinical trials. However, the PGA may not provide additional information for the assessment of individual patients.

\section{Declarations}

Funding There was no funding for this study.

Conflicts of interest/Competing interests Drs Baughman and Lower have research grants from Mallinckrodt, Bayer, Genentech, Novartis, Celgene, aTYR. Dr. Baughman has been consultant for Novartis and Mallinckrodt and a speaker for Mallinckrodt. Jacob Kotzin has no conflicts.

Availability of data and material upon request of corresponding author

Code availability no code needed

Authors' contributions All authors contributed to the study conception and design. Material preparation, data collection and analysis were performed by Robert Baughman and Jeffery Kotzin. The first draft of the manuscript was written by Robert Baughman and all authors commented on previous versions of the manuscript. All authors read and approved the final manuscript. 
Ethics approval The study was approved by the University of Cincinnati Institutional Review Board and registered on ClinicalTrials.gov (ClinicalTrials.gov Identifier: NCT02356445).

\section{References}

1. Victorson DE, Cella D, Grund H, Judson MA (2013) A conceptual model of health-related quality of life in sarcoidosis. Qual.Life Res.

2. Baughman RP, Drent M, Culver DA, Grutters JC, Handa T, Humbert M, Judson MA, Lower EE, Mana J, Pereira CA et al (2012) Endpoints for clinical trials of sarcoidosis. Sarcoidosis VascDiffuseLung Dis 29:90-98

3. Judson MA, Mack M, Beaumont JL, Watt R, Barnathan ES, Victorson DE (2015) Validation and Important Differences for the Sarcoidosis Assessment Tool. A New Patient-reported Outcome Measure. AmJRespirCrit Care Med 191:786-795

4. Patel AS, Siegert RJ, Creamer D, Larkin G, Maher TM, Renzoni EA, Wells AU, Higginson IJ, Birring SS (2013) The development and validation of the King's Sarcoidosis Questionnaire for the assessment of health status. Thorax 68:57-65

5. Baughman RP, Sweiss N, Keijsers R, Birring SS, Shipley R, Saketkoo LA, Lower EE (2017) Repository corticotropin for Chronic Pulmonary Sarcoidosis. Lung 195:313-322

6. Judson MA, Chaudhry H, Louis A, Lee K, Yucel R (2015) The effect of corticosteroids on quality of life in a sarcoidosis clinic: the results of a propensity analysis. RespirMed 109:526-531

7. Judson MA, Baughman RP, Costabel U, Drent M, Gibson KF, Raghu G, Shigemitsu H, Barney JB, Culver DA, Hamzeh NY et al (2014) Safety and efficacy of ustekinumab or golimumab in patients with chronic sarcoidosis. EurRespirJ 44:1296-1307

8. Obi ON (2020) Health-Related Quality of Life in Sarcoidosis. Semin.Respir Crit Care Med.101710080

9. Baughman RP, Judson MA, Beaumont JL, Maier LA, Sweiss NJ, Culver DA, Chen ES, Singh N, Lower $\mathrm{EE}$, Reeves $\mathrm{R}$ et al (2020) Evaluating the Minimal Clinically Important Difference of the King's Sarcoidosis Questionnaire (KSQ) in a Multi-center, Prospective Study. Ann.Am.Thorac.Soc.10-6070C

10. Hjermstad MJ, Fayers PM, Haugen DF, Caraceni A, Hanks GW, Loge JH, Fainsinger R, Aass N, Kaasa S (2011) Studies comparing Numerical Rating Scales, Verbal Rating Scales, and Visual Analogue Scales for assessment of pain intensity in adults: a systematic literature review. J Pain SymptomManage 41:1073-1093

11. Rahaghi FF, Baughman RP, Saketkoo LA, Sweiss NJ, Barney JB, Birring SS, Costabel U, Crouser ED, Drent M, Gerke AK et al (2020) Delphi consensus recommendations for a treatment algorithm in pulmonary sarcoidosis. Eur Respir Rev 29:29-155

12. Judson MA, Costabel U, Drent M, Wells A, Maier L, Koth L, Shigemitsu H, Culver DA, Gelfand J, Valeyre D et al (2014) The WASOG Sarcoidosis Organ Assessment Instrument: An update of a previous clinical tool. Sarcoidosis VascDiffuseLung Dis 31:19-27 
13. Harris PA, Taylor R, Thielke R, Payne J, Gonzalez N, Conde JG (2009) Research electronic data capture (REDCap)-a metadata-driven methodology and workflow process for providing translational research informatics support. JBiomedlnform 42:377-381

14. Straube S, Derry S, Moore RA, Paine J, McQuay HJ (2010) Pregabalin in fibromyalgia-responder analysis from individual patient data. BMCMusculoskeletDisord 11:150. doi:10.1186/1471-2474-11150.:150-11

15. Jones LE, Whitburn LY, Davey MA, Small R (2016) Numeric Scoring of Pain Still Has Value. AnnEmergMed 67:679-680

16. Vazirani J, Knott JC (2012) Mandatory pain scoring at triage reduces time to analgesia. AnnEmergMed 59:134-138

17. Silka PA, Roth MM, Moreno G, Merrill L, Geiderman JM (2004) Pain scores improve analgesic administration patterns for trauma patients in the emergency department. AcadEmergMed 11:264270

18. Green SM, Krauss BS (2016) The Numeric Scoring of Pain: This Practice Rates a Zero Out of Ten. AnnEmergMed 67:573-575

19. Sampson FC, Goodacre SW, O'Cathain A (2019) The Reality of Pain Scoring in the Emergency Department: Findings From a Multiple Case Study Design. AnnEmergMed 74:538-548

\section{Tables}

Table 1 Demographics and PGA scores for four treatment regimens at initial visit 


\begin{tabular}{|c|c|c|c|c|c|}
\hline & Total & $\begin{array}{c}\text { Increase } \\
\text { medications }\end{array}$ & $\begin{array}{c}\text { Reduce } \\
\text { medications }\end{array}$ & $\begin{array}{l}\text { No change in } \\
\text { medications }\end{array}$ & $\begin{array}{c}\text { No anti-inflammatory } \\
\text { medications }\end{array}$ \\
\hline $\begin{array}{l}\text { Total number of } \\
\text { patients }\end{array}$ & 677 & $241(35.6 \%)$ & 78 (11.5\%) & 267 (39.4\%) & 91 (13.4\%) \\
\hline Age (yrs) § & & $55.7+13.04 *$ & $55.4+11.07$ & $58.5+11.72$ & $57.5+12.60$ \\
\hline Age $<60$ years & 361 & 127 & 36 & 146 & 52 \\
\hline Age $\geq 60$ years & 316 & 114 & 42 & 121 & 39 \\
\hline \multicolumn{6}{|l|}{ Proportion of patients } \\
\hline Female & 453 & 168 & 50 & 175 & 60 \\
\hline Male & 224 & 73 & 28 & 92 & 31 \\
\hline African American & 287 & 101 & 33 & 120 & 33 \\
\hline White & 385 & 138 & 45 & 144 & 58 \\
\hline Asian & 3 & 1 & 0 & 2 & 0 \\
\hline Other & 2 & 1 & 0 & 1 & 0 \\
\hline \multicolumn{6}{|l|}{ Organ ๆ } \\
\hline Lung & 548 & 199 & 64 & 216 & 69 \\
\hline Eye & 234 & 85 & 28 & 92 & 29 \\
\hline Skin & 195 & 76 & 18 & 77 & 24 \\
\hline Calcium metabolism & 152 & 53 & 25 & 54 & 20 \\
\hline Neurosarcoidosis & 137 & 46 & 28 & 52 & 11 \\
\hline Liver & 97 & 39 & 10 & 38 & 10 \\
\hline $\begin{array}{l}\text { Non thoracic lymph } \\
\text { nodes }\end{array}$ & 91 & 35 & 9 & 33 & 14 \\
\hline Cardiac & 75 & 16 & 9 & 38 & 12 \\
\hline Spleen & 70 & 28 & 9 & 27 & 6 \\
\hline \multicolumn{6}{|l|}{$\begin{array}{l}\text { Anti-inflammatory } \\
\text { therapy I }\end{array}$} \\
\hline Prednisone & 283 & 114 & 60 & 109 & 0 \\
\hline Methotrexate & 159 & 54 & 28 & 77 & 0 \\
\hline Azathioprine & 42 & 16 & 8 & 18 & 0 \\
\hline Mycophenolate mofetil & 24 & 10 & 4 & 10 & 0 \\
\hline Leflunomide & 22 & 5 & 3 & 14 & 0 \\
\hline Hydroxychloroquine & 81 & 21 & 10 & 50 & 0 \\
\hline Infliximab & 77 & 19 & 17 & 41 & 0 \\
\hline Adalimumab & 18 & 4 & 4 & 10 & 0 \\
\hline Rituximab & 38 & 3 & 8 & 27 & 0 \\
\hline$\overline{\mathrm{RCI}}$ & 24 & 8 & 4 & 12 & 0 \\
\hline
\end{tabular}


$*$ Mean \pm standard deviation

I Patients could have more than one organ involved or more than one treatment

$\S$ Difference between groups by ANOVA, $\mathrm{p}<0.05$.

Table 2 Demographics and PGA scores for four treatment regimens at initial visit 


\begin{tabular}{|c|c|c|c|c|c|}
\hline & Total & $\begin{array}{c}\text { Increase } \\
\text { medications }\end{array}$ & $\begin{array}{c}\text { Reduce } \\
\text { medications }\end{array}$ & $\begin{array}{l}\text { No change in } \\
\text { medications }\end{array}$ & $\begin{array}{c}\text { No anti-inflammatory } \\
\text { medications }\end{array}$ \\
\hline $\begin{array}{l}\text { Total number of } \\
\text { patients }\end{array}$ & 677 & $241(35.6 \%)$ & 78 (11.5\%) & 267 (39.4\%) & $91(13.4 \%)$ \\
\hline \multicolumn{6}{|l|}{ PGA scores } \\
\hline All † & & $5.18 \pm 1.978$ * & $7.12+1.844$ & $7.38+1.828$ & $7.89+1.859$ \\
\hline Age $<60$ years $\dagger$ & & $5.29+1.903$ & $7.19+1.670$ & $7.24+1.836$ & $7.87+2.020$ \\
\hline Age $\geq 60$ years $\dagger$ & & $5.05+2.060$ & $7.05+1.999$ & $7.55+1.812$ & $7.92+1.644$ \\
\hline Female $†$ & & $5.05+2.001$ & $7.00+1.784$ & $7.18+1.950$ & $7.70+1.889$ \\
\hline Male † & & $5.47+1.908$ & $7.32+1.964$ & $7.76+1.507$ & $8.26+1.770$ \\
\hline African American † & & $5.47+2.194$ & $7.21+1.867$ & $7.42+1.930$ & $8.24+1.803$ \\
\hline White $\dagger$ & & $4.96+1.798$ & $7.04+1.846$ & $7.34+1.759$ & $7.69+1.875$ \\
\hline \multicolumn{6}{|l|}{ Organ involvement ๆ } \\
\hline Lung † & & $5.10++1.958$ & $7.08+1.846$ & $7.31+1.820$ & $8.00+1.774$ \\
\hline Eye $†$ & & $5.61+2.059$ & $7.11+1.729$ & $7.68+1.644$ & $7.93+2.034$ \\
\hline Skin $†$ & & $5.18+1.923$ & $7.33+1.879$ & $7.48+1.971$ & $7.46+2.166$ \\
\hline Calcium metabolism $\dagger$ & & $5.19+1.922$ & $6.52+1.874$ & $7.43+1.958$ & $7.55+2.012$ \\
\hline Neurosarcoidosis $†$ & & $5.04+2.139$ & $6.61+2.200$ & $7.27+1.548$ & $7.73+2.195$ \\
\hline Liver & & $4.85+1.710$ & $7.80+1.033$ & $7.45+1.927$ & $7.60+1.776$ \\
\hline $\begin{array}{l}\text { Non thoracic lymph } \\
\text { nodes } \ddagger\end{array}$ & & $6.00+1.831$ & $6.56+1.236$ & $7.55+1.769$ & $9.07+0.997$ \\
\hline Cardiac $* *$ & & $5.62+1.857$ & $7.22+2.108$ & $7.13+1.758$ & $7.33+2.461$ \\
\hline Spleen § & & $4.96+1.934$ & $7.56+1.333$ & $7.78+2.189$ & $8.67+0.816$ \\
\hline \multicolumn{6}{|l|}{ Current drugs ף } \\
\hline Prednisone †† & & $4.90+2.149$ & $7.10+1.829$ & $7.05+1.922$ & NA§§ \\
\hline Methotrexate †† & & $4.96+2.018$ & $6.79+1.950$ & $7.48+1.691$ & NA \\
\hline Azathioprine $+\dagger$ & & $4.69+2.024$ & $7.75+1.909$ & $8.11+1.023$ & NA \\
\hline Leflunomide †† & & $4.00+2.000$ & $8.00+1.000$ & $6.64+1.780$ & NA \\
\hline Mycophenolate †† & & $5.30+2.058$ & $7.50+1.000$ & $8.10+0.994$ & NA \\
\hline Hydroxychloroquine †† & & $4.86+2.080$ & $7.70+1.252$ & $7.58+2.043$ & NA \\
\hline Infliximab †† & & $4.84+1.803$ & $7.53+1.875$ & $7.56+1.582$ & NA \\
\hline Adalimumab †† & & $2.50+1.000$ & $6.25+2.986$ & $8.50+1.080$ & NA \\
\hline Rituximab & & $4.67+3.215$ & $6.50+1.852$ & $6.78+1.761$ & NA \\
\hline $\mathrm{RCI} \dagger+$ & & $4.38+2.134$ & $8.25+1.708$ & $7.67+1.614$ & NA \\
\hline
\end{tabular}

$*$ Mean \pm standard deviation

I Patients could have more than one organ involved or more than one treatment

†Difference between groups by ANOVA, $p<0.0001$. Those who increased medication were significantly different from other three groups by paired analysis $(\mathrm{P}<0.05)$. 
$\S$ Difference between groups by ANOVA, $\mathrm{p}<0.05$.

$\ddagger$ Difference between groups by ANOVA, $<<0.0001$. Those who increased medication were significantly different from no change and no anti-inflammatory medications by paired analysis $(\mathrm{P}<0.05)$.

** Difference between groups by ANOVA, $\mathrm{p}<0.01$. There was no difference between individual regimens by paired analysis.

†† Difference between groups by ANOVA, $\mathrm{p}<0.0001$. Those who increased medication were significantly different from reduced or no change in medication by paired analysis $(\mathrm{P}<0.05)$.

$\S \S \mathrm{NA}=$ not applicable

Table 3 PGA scores for increasing or decreasing anti-inflammatory medication versus indication for changing medications

\begin{tabular}{|c|c|c|c|c|c|}
\hline & & Sarcoidosis & Infection & Toxicity & Other \\
\hline \multicolumn{6}{|l|}{ Increase medication $\S$} \\
\hline & & $5.06+1.991 *$ & $4.91+1.771$ & $7.44+1.944$ & $6.33+1.723$ \\
\hline & $236 \dagger$ & 159 & 56 & 9 & 12 \\
\hline \multicolumn{6}{|l|}{ Reduce medication $\ddagger$} \\
\hline & & $7.74+1.678$ & 9 & $6.13+1.544$ & NA $* *$ \\
\hline & 75 & 43 & 1 & 31 & 0 \\
\hline
\end{tabular}

$*$ Mean \pm standard deviation

†Number of cases

$\S$ Difference between groups by ANOVA, $\mathrm{p}<0.001$. Those who increased or added new medication for toxicity had a higher PGA than those increased for sarcoidosis or acute infection by paired analysis $(\mathrm{P}<0.05)$.

¥ Difference between groups by ANOVA, $\mathrm{p}<0.001$. Those who reduced medication for sarcoidosis had a lower PGA than those who reduced for toxicity by paired analysis $(\mathrm{P}<0.05)$.

** NA=not applicable 